\title{
Nerve Growth Factor (NGF) Differentially Regulates the Chemosensitivity of Adult Rat Cultured Sensory Neurons
}

\author{
Stuart Bevan and Janet Winter \\ Sandoz Institute for Medical Research, London WC1E 6BN, United Kingdom
}

\begin{abstract}
We have studied the effects of NGF on the chemosensitivity of adult rat DRG neurons over a 1-2 week period in vitro, using voltage-clamp and radioactive ion flux methods. $A$ sustained proton evoked current was reversibly lost in NGF-free medium after 1 week. Proton-evoked efflux of radioactive ${ }^{86} \mathrm{Rb}^{+}$ions was also depressed in NGF deprived cultures, although depolarization with $40 \mathrm{~mm}$ potassium still evoked a large ${ }^{86} \mathrm{Rb}^{+}$efflux. A similar reversible loss of capsaicin sensitivity was noted. The response to GABA and a second, transient proton evoked current were also regulated by NGF, but over a longer time course. In contrast, the sensitivity to ATP was not influenced by the presence or absence of NGF. These data show that NGF regulates some, but not all, chemosensitivities of DRG neurons and that loss of sensitivity occurs at different rates for different agonists. The precise co-regulation of the response to capsaicin and the sustained response to protons provides further evidence that protons activate capsaicin-operated ion channels.
\end{abstract}

[Key words: dorsal root ganglion neurons, NGF, culture, capsaicin, protons, GABA, ATP]

NGF is required for the survival of the majority of embryonic sensory neurons (Johnson et al., 1980; Lindsay, 1988a; Crowley et al., 1994) and in the early postnatal rat can influence the differentiation of A $\delta$ (Ritter et al., 1991, 1993; Lewin et al., 1992a) and C nociceptive afferent fibers (Lewin and Mendell, 1992). In the adult rat, NGF deprivation does not cause significant sensory neuron death in vivo (Gorin and Johnson 1980; Ritter et al., 1991) and dorsal root ganglion (DRG) neurons cultured from adult animals do not need NGF for survival (Lindsay, 1988a,b). NGF can, however, increase the expression of substance $P$ and calcitonin gene related peptide (CGRP) in adult rat DRG neurons both in vivo (e.g., Wong and Oblinger, 1991) and in culture (Lindsay and Harmar, 1989; Lindsay et al., 1989). Furthermore, TTX resistant action potentials and responsiveness to capsaicin are lost when adult rat DRG neurons are cultured for 1-2 weeks in the absence of NGF (Winter et al., 1988, 1993; Aguayo and White, 1992).

Elevated levels of NGF are found in inflammatory conditions and this may be functionally important as systemic treatment of adult rats with NGF produces mechanical and thermal hyperal-

\footnotetext{
Received Nov. 21, 1994; revised Jan. 26, 1995; accepted Jan. 30, 1995.

We thank Jackie Donoghue for much of the cell culture work, Caroline Purvis for the $\mathrm{Rb}^{+}$efflux experiments, and $\mathrm{Dr}$. H. P. Kang for comments on the manuscript.

Correspondence should be addressed to Stuart Bevan, Sandoz Institute for Medical Research, 5 Gower Place, Lundon WCIE 6BN, United Kingdom. Copyright 1995 Society for Neuroscience $0270-6474 / 95 / 154918-09 \$ 05.00 / 0$
}

gesia (Lewin et al., 1993). Thermal hyperalgesia develops within minutes of exogenous NGF administration and could involve a direct sensitization of mechanoheat-sensitive fibers. Mechanical hyperalgesia develops over a period of hours and may be due to changes within the spinal cord, such as increased substance P release from central afferent terminals (Lewin et al., 1992b). Moreover, NGF neutralizing antibodies greatly attenuate the thermal and mechanical hyperalgesia induced by complete Freund's adjuvant (Woulf et al., 1994). Conversely, sensory neurons may be exposed to lower than normal levels of NGF in certain neuropathic conditions and this may contribute to the pathophysiology (Brewster et al., 1994).

DRG neurons are sensitive to a range of chemical agents (Rang et al., 1991), including ATP, bradykinin, 5-HT, ACh, and protons (low $\mathrm{pH}$ ), which excite sensory neurons and evoke the sensation of pain, as well as GABA, which is not painful. We have therefore examined if the modulation of chemosensitivity by NGF was restricted to capsaicin or extended to other chemical activators. This investigation also allowed us examine whether or not exposure to elevated levels of NGF, which occur in inflammation, would increase chemosensitivity and thereby contribute to the hyperalgesia. In this article we show that (1) the expression of two types of proton-activated currents is regulated by NGF with different time courses, (2) GABA sensitivity is reduced slowly in the absence of NGF; and (3) ATP sensitivity is NGF independent. Thus, sensitivity to different chemical agents appears to be regulated by NGF in a selective manner.

\section{Materials and Methods}

Adult DRG neuron cultures. Neurons were isolated and grown by methods that have been described in detail previously (Lindsay, 1988b Wood et al., 1988) with slight modifications. Spinal columns were re moved aseptically from $\mathrm{CO}_{2}$-asphyxiated adult Sprague-Dawley rats (>8 weeks old, 180-200 gm) and DRG were dissected from all spinal levels. Ganglia were digested with $0.125 \%$ collagenase (Boehringer Mannheim UK) in Ham's F-14 medium (Imperial Laboratories UK) containing 4\% US-G (Ultraser-G serum substitute from $\mathrm{GIBCO} / \mathrm{Be}-$ thesda Research Labs, UK) for 90 min then for a further 90 min in fresh collagenase solution at $37^{\circ} \mathrm{C}$. After being washed with US-Gcontaining medium, ganglia were triturated through a flame-polished Pasteur pipette to form a single-cell suspension. DRG neurons were then plated either on $35 \mathrm{~mm}$ tissue culture plastic petri dishes (approximate density 20,000 neurons/dish) or on $13 \mathrm{~mm}$ glass coverslips $(10,000$ neurons/coverslip). Dishes and coverslips had been previously coated with polyornithine and laminin (GIBCO/Bethesda Research Labs, UK). Cultures were treated with the mitotic inhibitor cytosine arabinoside to reduce the non-neuronal cell population and grown in F14 plus 4\% US-G. Two protocols were used to study the effects of NGF deprivation. In the first, the culture medium was supplemented with either rat monoclonal 23c4 anti-NGF (Weskamp and Otten, 1983) $50 \mu \mathrm{g} / \mathrm{ml}$ (sufficient to block $200 \mathrm{ng} / \mathrm{ml} \mathrm{NGF)} \mathrm{or} \mathrm{with} 200 \mathrm{ng} / \mathrm{ml} 2.5 \mathrm{~S}$ NGF purified from mouse submaxillary gland plus a control rat monoclonal antibody (Y13-238, anti-ras21; Furth et al., 1982) of the same 
Table 1. Comparison of the chemosensitivities of freshly dissociated and cultured $(200 \mathrm{ng} / \mathrm{ml}$ NGF) DRG neurons

\begin{tabular}{lllll} 
& $\begin{array}{l}\text { Freshly } \\
\text { dissociated }\end{array}$ & $\begin{array}{l}\text { 1 week } \\
\text { (all expts) }\end{array}$ & $\begin{array}{l}\text { 2 weeks } \\
\text { (all expts) }\end{array}$ \\
\hline Capsaicin $(500 \mathrm{nM})$ & $P(R)$ & $48 \%(23 / 48)$ & $48 \%(65 / 135)$ & $49 \%(17 / 35)$ \\
& $A(\mathrm{tot})(\mathrm{nA})$ & $0.63 \pm 0.20$ & $0.67 \pm 0.10$ & $0.71 \pm 0.22$ \\
& $A(R)(\mathrm{nA})$ & $1.32 \pm 0.37$ & $1.40 \pm 0.18$ & $1.47 \pm 0.39$ \\
pH 5.8, sustained & $P(R)$ & $47 \%(36 / 76)$ & $49 \%(67 / 138)$ & $49 \%(17 / 35)$ \\
& $A($ tot $)(\mathrm{nA})$ & $0.66 \pm 0.16$ & $0.83 \pm 0.13$ & $0.90 \pm 0.32$ \\
& $A(R)(\mathrm{nA})$ & $1.41 \pm 0.28$ & $1.70 \pm 0.22$ & $1.57 \pm 0.57$ \\
pH 5.8, transient & $P(R)$ & $53 \%(46 / 87)$ & $67 \%(92 / 138)$ & $65 \%(111 / 172)$ \\
& $A($ tot $)(\mathrm{nA})$ & $1.36 \pm 0.27$ & $1.08 \pm 0.16$ & $1.24 \pm 0.16$ \\
GABA $(100 \mu \mathrm{M})$ & $A(R)(\mathrm{nA})$ & $2.57 \pm 0.45$ & $1.62 \pm 0.23$ & $1.94 \pm 0.22$ \\
& $P(R)$ & $92 \%(45 / 49)$ & $82 \%(22 / 27)$ & $92 \%(84 / 91)$ \\
& $A($ tot $)(\mathrm{nA})$ & $1.67 \pm 0.32$ & $1.20 \pm 0.23$ & $0.78 \pm 0.09 *$ \\
ATP $(10 \mu \mathrm{M})$ & $A(R)(\mathrm{nA})$ & $1.82 \pm 0.34$ & $1.47 \pm 0.24$ & $0.85 \pm 0.10^{* *}$ \\
& $P(R)$ & $78 \%(32 / 41)$ & $75 \%(18 / 24)$ & $90 \%(115 / 128)$ \\
& $A($ tot $)(\mathrm{nA})$ & $1.56 \pm 0.36$ & $1.18 \pm 0.27$ & $0.75 \pm 0.08$ \\
& $A(R)(\mathrm{nA})$ & $2.00 \pm 0.43$ & $1.57 \pm 0.33$ & $0.83 \pm 0.09 \div$
\end{tabular}

No statistically significant changes in $P(R), A(t o t)$, and $A(R)$ were noted for capsaicin- and both transient and sustained proton-evoked responses $(P>0.05)$. A(R) was significantly reduced for both GABA and ATP responses $(P<0.01)$. Probabilities of differences between cultured and freshly dissociated neurons: $*,<0.05 ; * *,<0.01$; $t_{1}<0.001$. In some experiments, neurons were challenged with brief $(2.5 \mathrm{sec})$ applications of low $\mathrm{pH}$ medium. In these cases the amplitude of any abbreviated sustained response was not measured.

subtype as $23 \mathrm{c} 4$. In the second set of experiments, $50 \mathrm{ng} / \mathrm{ml}$ NGF (Promega) was added to both sets of cultures but one received the neutralizing (23c4) and the other the control (Y13-238) antibody. Both antibodies were purified from ascites fluid from nude mice that had been injected with the appropriate hybridomas. Some neurons were grown initially in NGF-deprived conditions (no added NGF plus neutralizing antibody), then switched into NGF-containing medium for a further period. Medium was changed every 3-4 d.

Electrophysiology. Acutely dissociated DRG neurons were maintained in medium without added NGF and studied electrophysiologically $6-18 \mathrm{hr}$ after dissociation. In other experiments designed to test the effects of NGF, neurons were grown with or without NGF for 6-7 $\mathrm{d}$ (grouped as 1 week) or 12-16 d (grouped as 2 weeks). For one part of the study neurons were grown without NGF for 1 week and switched into NGF containing medium for a further week. In the early experiments, cells were removed from the petri dishes by trituration through a Pasteur pipette after a short incubation in trypsin $(0.05 \%)$ They were then replated on $13 \mathrm{~mm}$ glass coverslips that had been previously coated with polyornithine. In later experiments, no enzymes were used and cells were removed mechanically from the petri dish, triturated and replated as before. For each experiment one batch of neurons were used as an "age matched" control and were cultured with NGF for the entire period. This provided an internal control for any possible difference in measured chemosensitivity between different DRG neuron preparations and experiments. Results from at least three independent experiments were obtained for each part of the investigation.

Cell diameters were measured microscopically. Two orthogonal measurements were made for each cell studied electrophysiologically and the mean calculated. No attempt was made to select for any particular cell size. The neuronal population, however, showed very few large diameter $(>50 \mu \mathrm{m})$ cells; these may have been selectively lost in the cell preparation and replating procedures used. The mean diameter of cells cultured with NGF $(24.25 \mu \mathrm{m})$ is very similar to the mean diameter $(24.53 \mu \mathrm{m})$ of the major neuronal population ( $>93 \%$ of cells) measured in fixed cultured DRG neurons (Winter, 1987).

Recordings from cultured neurons were made between 16 and 24 hours after the neurons were replated. Before $8 \mathrm{hr}$ the responses to capsaicin and low $\mathrm{pH}$ showed a great variability in their occurrence, but not their time course, and some preparations failed to respond to these agents even though the neurons responded before replating (data not shown). A likely explanation for this is that these receptors are located preferentially on the neurites of cultured cells and that after replating some time is required for the new receptors to be expressed on the surface of the soma. After 16-24 hr, the neurons elaborated few, if any, neurites and could still be studied easily. At longer times neurites were extended and the neurons could not be adequately voltage clamped.

Whole cell "tight seal" recordings were made from neurons with wide bore patch pipettes ( $2-5 \mathrm{M} \Omega$ ). The methods used are described in detail in Bevan and Yeats (1991); experiments were carried out at 21$23^{\circ} \mathrm{C}$. The basic external solution contained (mM) $130 \mathrm{NaCl}, 5 \mathrm{KCl}, 2$ $\mathrm{CaCl}_{2}, 1 \mathrm{MgCl}_{2}, 40$ sucrose, 5 glucose and was usually buffered to $\mathrm{pH}$ 7.4 with $10 \mathrm{~mm}$ HEPES titrated with $\mathrm{NaOH}$. A $10 \mathrm{~mm}$ HEPES buffer was also used for solutions of $\mathrm{pH}$ 6.8-8.2. More acidic solutions used either $10 \mathrm{~mm}$ MES (pH 5.0-5.8) or $10 \mathrm{~mm}$ PIPES (pH 6.6) as the buffer. Drugs or low $\mathrm{pH}$ solutions were rapidly applied from a "Utube" (Fenwick et al., 1984) for either 2.5 or $5-7.5 \mathrm{sec}$. DMSO (1\%) was included in both the bath and drug solutions when capsaicin sensitivity was tested to ensure that capsaicin remained in solution. Currents were usually recorded at a relatively low gain $(1-2 \mathrm{mV} / \mathrm{pA})$ and the limit of detection for an agonist induced current was 20-30 pA. Neurons with evoked currents less than this value were classed as nonresponsive. Sequential challenges of single DRG neurons with different agents were made with intervals of $2 \mathrm{~min}$. With this protocol we avoided any potentiation of the capsaicin response by acidic external media (Petersen and LaMotte, 1993)

${ }^{86} R b^{+}$efflux experiments. Adult DRG neurons were grown at a density of approximately 10,000 per $13 \mathrm{~mm}$ coverslip, for 1 or 2 weeks, with or without NGF as described above. Cells were then incubated with 2 $\mathrm{mCi} / \mathrm{ml}$ of ${ }^{86} \mathrm{RbCl}(300 \mathrm{mCi} / \mathrm{mmol}$; Amersham UK) for $2-4 \mathrm{hr}$, placed in a perfusion chamber (volume $0.5 \mathrm{ml}$ ), and washed for $30 \mathrm{~min}$ with Hanks's BSS $5 \mathrm{~mm}$ HEPES (pH 7.4) at a perfusion rate of $1 \mathrm{ml} / \mathrm{min}$. Perfusate fractions $(1 \mathrm{ml})$ were collected directly into scintillation vials, and cells were challenged sequentially with low $\mathrm{pH}$ buffer $(\mathrm{pH} 5.4,5$ $\mathrm{mM} \mathrm{MES}$ ), high $\mathrm{KCl}(40 \mathrm{~mm})$ and $10 \mathrm{~mm}$ capsaicin, each for $3 \mathrm{~min}$, with a wash in $\mathrm{pH} 7.4 \mathrm{BSS}$ after each challenge. Cultures were then dissolved with $0.2 \%$ SDS (sodium dodecyl sulfate) to measure ${ }^{86} \mathrm{Rb}^{+}$ remaining in the cells. Experiments were carried out at room temperature $\left(21-23^{\circ} \mathrm{C}\right)$. The radioactivity in the perfusate fractions and the cells was measured in a liquid scintillation counter. Four coverslips were sampled for each point.

Statistics. Changes in resting potential, cell capacitance and size were analyzed with Student's $t$ test. The current amplitudes were not normally distributed and so nonparametric tests were used, although values are expressed as mean \pm SEM to give some indication of the scatter in the values. Differences in current amplitudes were usually analyzed by the Mann-Whitney $U$ test. Paired observations in single neurons were compared with the Wilcoxon matched pairs test. Proportions of respond- 
ing and non-responding cells were examined with the $\chi^{2}$ test with Yates's correction for continuity except when the expected number in any category was 5 or less when Fisher's exact test was employed.

\section{Results}

Changes in chemosensitivity of neurons in culture may result from a change in the proportion of neurons that is responsive $[P(R)]$, and a change in the mean response amplitude measured for the total population $[\Lambda($ tot $)]$ or for the responsive population $[A(R)]$. We have studied the effects of NGF on DRG neuron chemosensitivity in terms of these three parameters.

\section{Sensitivity of freshly isolated DRG neurons}

The chemosensitivity of DRG neurons was measured within 18 hr of isolation and provided a comparison for any subsequent changes in neuronal properties. The types of currents evoked by the various chemical agents were identical to those seen after 1 or 2 weeks in culture. Acidification of the external medium to $\mathrm{pH} 5.8$ evoked either one or two types of inward current in responsive neurons at $-80 \mathrm{mV}$ (fast, transient, and slow, sustained currents). Inward currents were also evoked in some, but not all, neurons by capsaicin (500 nM), ATP $(10 \mu \mathrm{M})$, and GABA $(100 \mu \mathrm{M})$. Table 1 shows the chemosensitivity of freshly isolated neurons as well as neurons cultured for either 1 or 2 weeks in the presence of NGF $(50-200 \mathrm{ng} / \mathrm{ml})$. The sensitivity to capsaicin and $\mathrm{pH} 5.8$ medium (both currents) was not altered by up to 2 weeks in culture $(P>0.5$ for $A($ tot $), A(R)$, and $P(R)$ in all cases). Changes were noted in the sensitivity to ATP and GABA with time in culture. Although $P(R)$ did not differ significantly $(P>0.05), A(R)$ decreased over the 2 week culture period to $42 \%$ (ATP) and $47 \%$ (GABA) of the values seen in freshly isolated neurons ( $P<0.01$, Kruskall-Wallis test). In view of these time-dependent changes in chemosensitivity and the possibility of small differences in responses between different preparations of DRG neurons, we have studied the effects of NGF by comparing the sensitivity of approximately equal numbers of NGF-treated $\left(\mathrm{NGF}^{+}\right)$and $\mathrm{NGF}$-deprived $\left(\mathrm{NGF}^{-}\right)$neurons from a given preparation after the same time in culture. In all cases, at least three preparations were used to obtain any given result.

\section{Effects of NGF deprivation}

Two experimental protocols were used to investigate the effects of NGF on DRG neuron properties. In the first series of experiments, two sets of sister cultures were studied. NGF was omitted from one set and a neutralizing anti-NGF monoclonal antibody added to eliminate any effects of NGF produced by cells in the culture. The other set received $200 \mathrm{ng} / \mathrm{ml}$ of $\mathrm{NGF}$ plus a control monoclonal antibody of the same immunoglobulin subclass. In the second series of experiments, both sets of cultures were treated with $50 \mathrm{ng} / \mathrm{ml} \mathrm{NGF}$; however, neutralizing antibody was added to one set and control antibody added to the other set. The results obtained with the two protocols were indistinguishable and have been pooled to aid presentation. Neurons exposed to NGF have been designated $\mathrm{NGF}^{+}$and those cultured either without added NGF or with NGF neutralized termed $\mathrm{NGF}^{-}$.

\section{Low $p H$}

A typical response to a challenge with an acidic solution $(\mathrm{pH}$ 5.8 ) is illustrated in Figure $1 a$ for a neuron that had been grown for 1 week in the presence of NGF. The two components of the
$\mathrm{pH} 5.8$

500nM Capsaicin
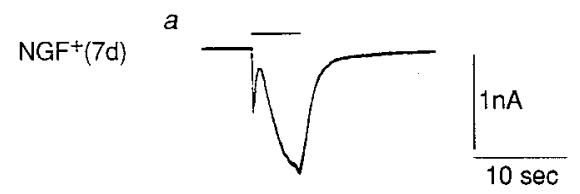

$b$
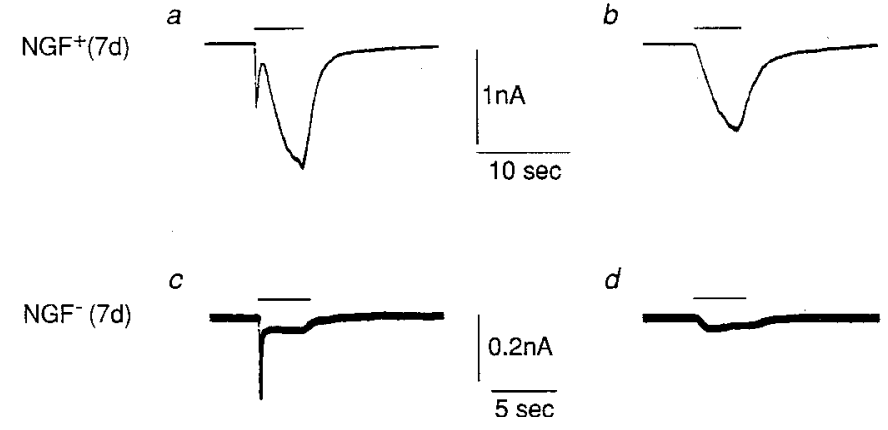

d

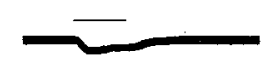

$\operatorname{NGF}^{-}(6 \mathrm{~d})$

$e$
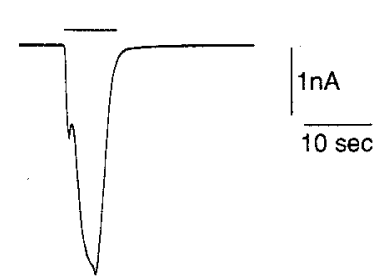

$f$

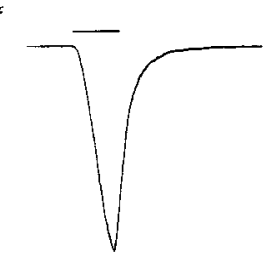

Figure 1. Current responses to pH $5.8(a, c, e)$ and $500 \mathrm{~nm}$ capsaicin $(b, d, f)$ in DRG neurons cultured for 1 week with either $\operatorname{NGF}(a, b)$ present or no added NGF plus neutralizing antibody to NGF $(c, d)$. Traces in $e$ and $f$ show the recovery of the capsaicin and sustained, low $\mathrm{pH}$ responses when neurons were first grown without NGF for 1 week and then re-exposed to NGF for a further week. The transient proton evoked currents can also be seen in traces $a, c$, and $e$. Traces $a$ and $b$, $c$ and $d$, and $e$ and $f$ were obtained from individual cells sequentially challenged at 2 min intervals. Horizontal bars represent the time of agonist application.

response (transient and sustained) can be clearly seen. $P(R)$ was always greater for the transient current than for the sustained current so that some neurons displayed only the transient current (see Fig. $3 a, b$ ). Although recent studies have shown that the transient current in rat trigeminal ganglion neurons can be separated into three kinetic components (Pidoplichko, 1992), we found no clear evidence for multiple transient currents in our studies and have used the total transient current for our analyses.

Sustained proton-evoked current. The sustained response was influenecd by the presence of NGF as illustrated by the results shown in Table 2. $P(R)$ was $48.6 \%$ for $\mathrm{NGF}^{+}$neurons but only $14.9 \%$ for $\mathrm{NGF}^{-}$neurons after 1 week in culture. The mean amplitude of the response was also diminished in the NGFcultures (Figs. 1c, 2). $A($ tot) and $A(R)$ were reduced to $16.9 \%$ and $48.4 \%$ of the values seen in $\mathrm{NGF}^{+}$neurons.

(1) NGF does not alter $p H$ activation. One possible explanation for the smaller number of cells responding to $\mathrm{pH} 5.8$ medium in $\mathrm{NGF}^{-}$cultures was that the $\mathrm{pH}$ sensitivity of the cells had been shifted in the direction of more acidic solutions. This was tested by challenging neurons with $\mathrm{pH} 5.2$ medium as well as $\mathrm{pH} 5.8$ medium. In this experiment, 7 out of $9 \mathrm{NGF}^{+}$neurons responded to the low $\mathrm{pH}$ solutions. $A(R)$ was greater $(P<0.05)$ with pH 5.2 medium $(0.85 \pm 0.23 \mathrm{nA})$ than with $\mathrm{pH} 5.8 \mathrm{me}$ dium $(0.38 \pm 0.12 \mathrm{nA})$. In contrast, significantly fewer ( 1 out of $12, P<0.01$ ) $\mathrm{NGF}^{-}$neurons showed a detectable sustained response to $\mathrm{pH}$ 5.2. Thus, the stronger $\mathrm{pH}$ stimulus did not succeed in causing responses in $\mathrm{NGF}^{-}$neurons.

(2) NGF effects are reversible. Experiments were carried out to determine if the reduction in proton sensitivity was reversible, 
Table 2. Effect of NGF deprivation for 1 week on the sustained, low pH- and capsaicin-evoked currents

\begin{tabular}{lllll} 
& & $\begin{array}{l}\mathrm{NGF}^{+} \\
(1 \text { week })\end{array}$ & $\begin{array}{l}\mathrm{NGF}^{-} \\
(1 \text { week }\end{array}$ & $\begin{array}{l}\text { Ratio }_{\mathrm{NGF}^{-}} \\
\mathrm{NGF}^{+}\end{array}$ \\
\hline pH-sustained & $P(R)$ & $48.6 \%(67 / 138)$ & $14.9 \%(17 / 114) \dagger$ & \\
& $A($ tot $)(\mathrm{nA})$ & $0.83 \pm 0.13$ & $0.14 \pm 0.05 \dagger$ & $16.9 \%$ \\
Capsaicin & $A(R)(\mathrm{nA})$ & $1.70 \pm 0.22$ & $0.92 \pm 0.26^{*}$ & $48.4 \%$ \\
& $P(R)$ & $48.1 \%(65 / 135)$ & $14.1 \%(16 / 113) \dagger$ & \\
& $A(\mathrm{tot})(\mathrm{nA})$ & $0.67 \pm 0.10$ & $0.11 \pm 0.04 \dagger$ & $16.4 \%$ \\
& $A(R)(\mathrm{nA})$ & $1.40 \pm 0.18$ & $0.81 \pm 0.24$ & $57.9 \%$ \\
\hline
\end{tabular}

Values for $\mathrm{P}(\mathrm{R}), \mathrm{A}(\mathrm{tot})$, and $\mathrm{A}(\mathrm{R})$ shown for 1 week $\mathrm{NGF}^{+}$and $\mathrm{NGF}^{-}$cultures. Probabilities of difference between $\mathrm{NGF}^{+}$and $\mathrm{NGF}^{-}$cultures; $*,<0.05 ; \dagger,<0.01$. No symbol indicates $P>0.05$.

as previously reported for the effects of NGF on capsaicin sensitivity (Winter et al., 1988). DRG neurons were cultured first for 1 week in medium without NGF and then for a further week with $\mathrm{NGF}\left(\mathrm{NGF}^{-1+}\right)$. The response to $\mathrm{pH} 5.8$ solution was compared to that of $\mathrm{NGF}^{+}$neurons cultured for 2 weeks. $\mathrm{NGF}^{-1+}$ neurons regained at least part of their proton sensitivity and large current responses were recorded in some neurons (Fig. 1e). This increase in sensitivity was reflected by changes in both the proportion of responsive neurons and the sizes of the responses (Table 3). 59\% of the $\mathrm{NGF}^{-1+}$ neurons showed the sustained proton-activated current, which is a significantly larger proportion than observed in 1 week $\mathrm{NGF}^{-}$cultures $(14.9 \%$, see Table 2, $P<0.0001)$ and similar to the $P(R)$ seen in 1 week $\mathrm{NGF}^{+}$ cultures $\left(49 \%\right.$, see Table $2, P>0.3$ ) and 2 week $\mathrm{NGF}^{+}$cultures (49\%, Table 3, $P>0.4$ ). A(tot) was significantly larger in

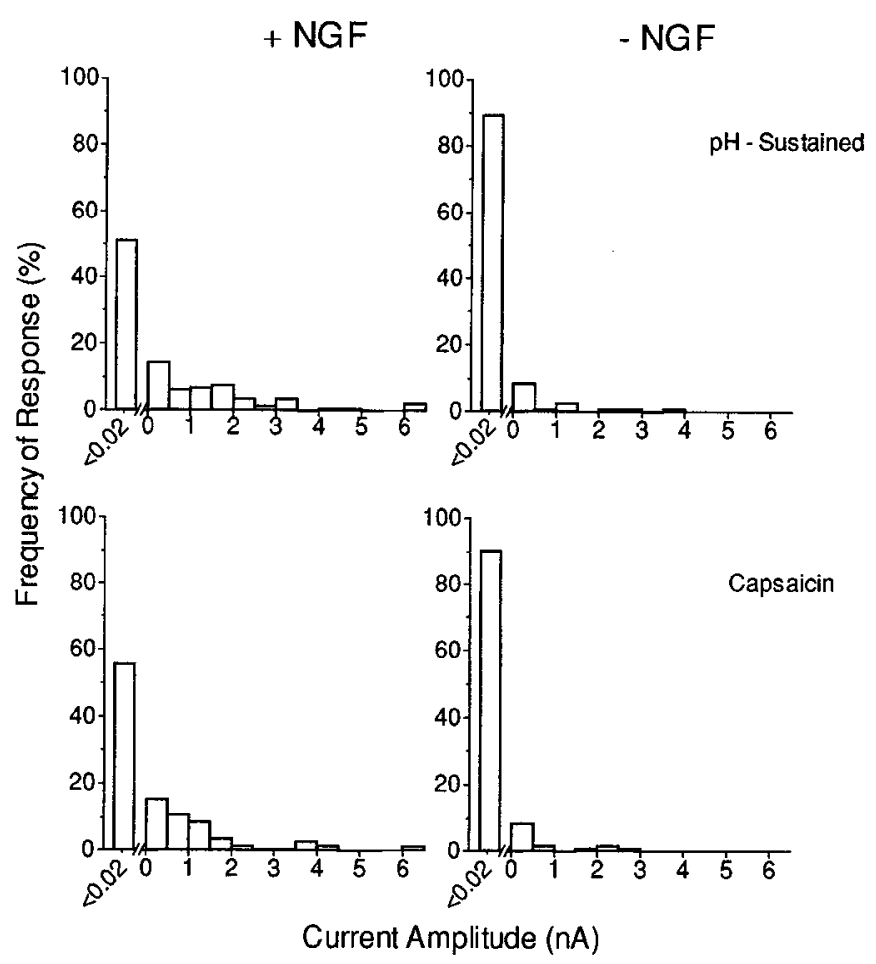

Figure 2. Frequency distributions of amplitudes of the sustained, low $\mathrm{pH}$ - (top) and capsaicin-evoked currents (bottom) after 1 week in culture either with NGF (left) or without NGF (right). Left-hand bars show percentage of neurons with no measurable current $(<20-30 \mathrm{pA})$. Results correspond to amplitudes given in Table 2.
$\mathrm{NGF}^{-1+}$ neurons $(0.45 \pm 0.17 \mathrm{nA}, n=29)$ than in 1 week $\mathrm{NGF}^{-}$ncurons $(0.14 \pm 0.05 \mathrm{nA}, P<0.0001)$, but not significantly different from the value seen in 2 week $\mathrm{NGF}^{+}$cultures $(0.90 \pm 0.32 \mathrm{nA}, P>0.1)$.

Transient proton-evoked current. The transient current evoked by acidic solutions (Figs. $1 a, c ; 3 a, b$ ) was also modulated when the neurons were deprived of NGF (Table 4). $P(R)$ was not significantly altered after either 1 or 2 weeks culture in $\mathrm{NGF}^{-}$medium $(P>0.05$ ), but the amplitude of the current response was reduced progressively in $\mathrm{NGF}^{-}$neurons (see Figs. $\left.3 a, b ; 4\right)$ ). After 1 week, $A$ (tot) and $A(R)$ were $72.2 \%$ and $71.6 \%$ of the values found in $\mathrm{NGF}^{+}$neurons and these percentages were significantly reduced to $25.5 \%$ and $28.6 \%$ after 2 weeks in culture (Table 4 ).

(1) NGF does not influence activation or inactivation. The transient proton activated current in chick DRG neurons has been shown to inactivate at acidic or even neutral pH (Konnerth et al., 1987) and the number of available ion channels is maximum at $\mathrm{pH}>7.8$. One possible explanation for the reduced size of the transient current in $\mathrm{NGF}^{-}$neurons was a greater degree of inactivation at $\mathrm{pH} 7.4$. However, there was no obvious difference in the $\mathrm{pH}$ inactivation curves when 2 week $\mathrm{NGF}^{+}$and $\mathrm{NGF}^{-}$neurons were challenged with $\mathrm{pH} 5.8$ medium from different resting $\mathrm{pH}$ levels $(\mathrm{pH} 7.0,7.8,8.2$; see Fig. 5). In both cases half-inactivation was observed at about $\mathrm{pH} 7.1$ and currents were nearly maximal at $\mathrm{pH} 7.4$. In other experiments neurons were bathed in $\mathrm{pH} 7.8$ medium to activate the current maximally and the external $\mathrm{pH}$ was stepped to $\mathrm{pH}$ 5.8. Transient currents were evoked in a similar proportion of 2 week $\mathrm{NGF}^{+}$ and $\mathrm{NGF}^{-}$neurons $\left[P(R): 75 \% \mathrm{NGF}^{+}, n=20\right.$ and $59 \% \mathrm{NGF}^{-}$, $n=17 ; P>0.4]$ and once again $A(R)$ in $\mathrm{NGF}^{+}$neurons $(2.25$ $\pm 0.55 \mathrm{pA})$ was larger than in $\mathrm{NGF}^{-}$neurons $(0.31 \pm 0.07 \mathrm{pA}$, $P<0.01$ ).

Neurons were also challenged with $\mathrm{pH} 5.2$ as well as the $\mathrm{pH}$ 5.8 solution to test if the reduced transient response was due to a shift in the $\mathrm{pH}$-response curve. After 1 week in $\mathrm{NGF}^{+}$medium, $A(R)$ was similar with $\mathrm{pH} 5.8(0.95 \pm 0.26 \mathrm{nA})$ and $\mathrm{pH} 5.2$ solutions $(1.11 \pm 0.25 \mathrm{nA}, n=8, P>0.05)$. Although the $P(R)$ value for responses to $\mathrm{pH} 5.2$ medium was not significantly reduced in the $\mathrm{NGF}^{-}$neurons $(45 \%, n=11 P>0.05), A(R)$ $(0.36 \pm 0.07 \mathrm{nA})$ was reduced compared to the $\mathrm{NGF}^{+}$cells $(P$ $<0.05)$.

\section{Capsaicin sensitivity}

The sensitivity of DRG neurons to capsaicin is known to be regulated by NGF and was used as a control for the effects of NGF on other chemosensitivities. Responses to $500 \mathrm{~nm}$ capsa- 
Table 3. Reversible effects of NGF on capsaicin-evoked currents and the sustained low pHevoked current

\begin{tabular}{lllll} 
& & $\begin{array}{l}\mathrm{NGF}^{+} \\
(2 \text { weeks })\end{array}$ & $\begin{array}{l}\text { NGF } \\
(1 \text { week/1 week })\end{array}$ & $\begin{array}{l}\text { Ratio } \\
\mathrm{NGF}^{+/+} \\
\mathrm{NGF}^{+}\end{array}$ \\
\hline pH-sustained & $P(R)$ & $49 \%(17 / 35)$ & $59 \%(17 / 29)$ & \\
& $A($ tot $)(\mathrm{nA})$ & $0.90 \pm 0.32$ & $0.45 \pm 0.17$ & $50.0 \%$ \\
Capsaicin & $A(R)(\mathrm{nA})$ & $1.57 \pm 0.57$ & $0.97 \pm 0.33 \mathrm{nA}$ & $61.8 \%$ \\
& $P(R)$ & $49 \%(17 / 35)$ & $50 \%(15 / 30)$ & \\
& $A($ tot $)(\mathrm{nA})$ & $0.71 \pm 0.22$ & $0.39 \pm 0.14$ & $54.9 \%$ \\
& $A(R)(\mathrm{nA})$ & $1.47 \pm 0.39$ & $1.00 \pm 0.31$ & $68.0 \%$
\end{tabular}

Responses of 2 week $\mathrm{NGF}^{+}$neurons are compared with the responses of neurons from the same cell preparation deprived of NGF for 1 week and then re-exposed to NGF for 1 week $\left(\mathrm{NGF}^{-1+}\right)$. No statistical differences $(P>$ $0.05)$ in $\mathrm{P}(\mathrm{R}), \mathrm{A}($ tot $)$, and $\mathrm{A}(\mathrm{R})$ were seen between $\mathrm{NGF}^{+}$and $\mathrm{NGF}^{-1+}$ neurons.

icin were monophasic (Fig. 1) and we found no evidence for the multiple currents reported by Lui and Simon (1994) in rat trigeminal ganglion neurons. In 1 week $\mathrm{NGF}^{+}$cultures, $48.1 \%$ of the neurons responded to $500 \mathrm{nM}$ capsaicin with a detectable inward current (Table 2). In contrast, $P(R)$ was only $14.1 \%$ in 1 week $\mathrm{NGF}^{-}$cultures $(P<0.001)$. The mean amplitude of the current was reduced in $\mathrm{NGF}^{-}$neurons with $A($ tot) only $16.4 \%$ of the amplitude observed in $\mathrm{NGF}^{+}$neurons. Although the currents in the responsive $\mathrm{NGF}^{-}$neurons were in general smaller than in $\mathrm{NGF}^{+}$neurons (Fig. 2), some $\mathrm{NGF}^{-}$neurons showed a robust response to capsaicin. The presence of these large responses was reflected in the $A(R)$ value which was $57.9 \%$ of that in $\mathrm{NGF}^{+}$neurons $(P=0.06$; see Table 2$)$. A further observation was that all the $\mathrm{NGF}^{-}$neurons that responded to the low $\mathrm{pH}$ solution also responded to capsaicin with similar current am-

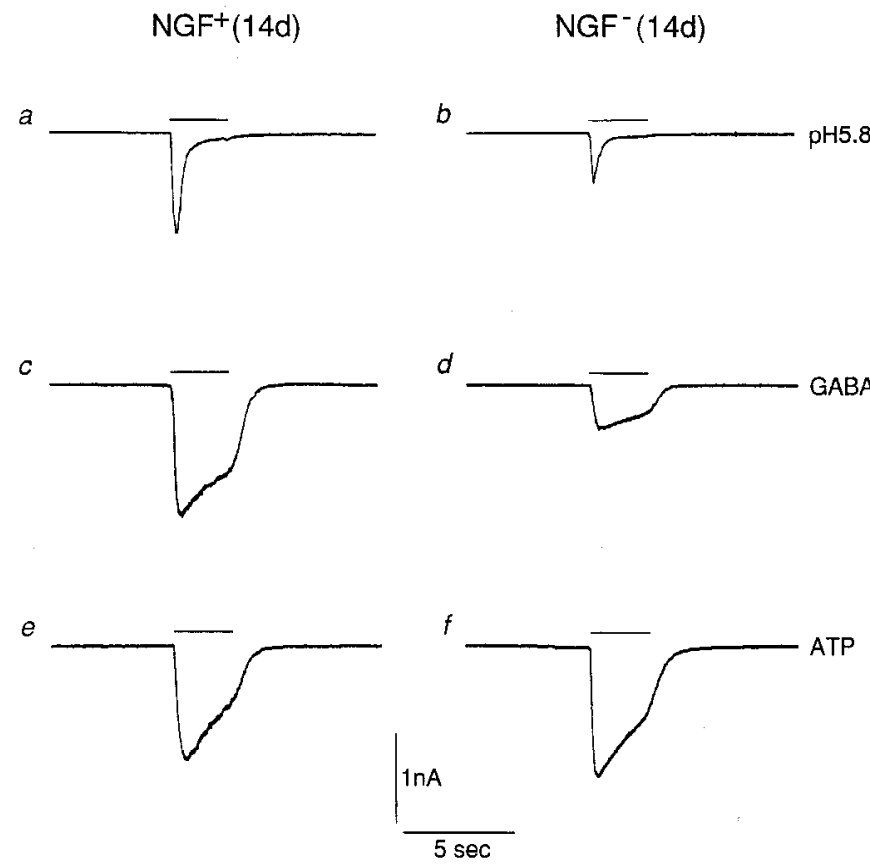

Figure 3. Transient low $\mathrm{pH}$ evoked currents in the absence of the sustained proton evoked response $(a, b)$ and responses to GABA $(c, d)$ and $\operatorname{ATP}(e, f)$. Neurons cultured for 2 weeks with $\operatorname{NGF}(a, c, e)$ or in NGF-free media $(b, d, f)$. The responses in $a$ and $b$ are examples of neurons that show only one type of proton chemosensitivity. Horizontal bars represent the time of agonist application. plitudes (Fig. 2). This is reflected in the similar $P(R)$ and $A(R)$ values for the two agonists (see Table 2).

Capsaicin sensitivity was regained when NGF was added back to the cultures (Table 3 ) and many neurons showed large current responses (Fig. $1 f$ ). $P(R)$ increased to $59 \%$ in $\mathrm{NGF}^{-1+}$ cultures, which is similar to the value in control, 2 week $\mathrm{NGF}^{+}$cultures (49\%). $A$ (tot) was significantly greater in $\mathrm{NGF}^{-1+}(0.39+0.14$

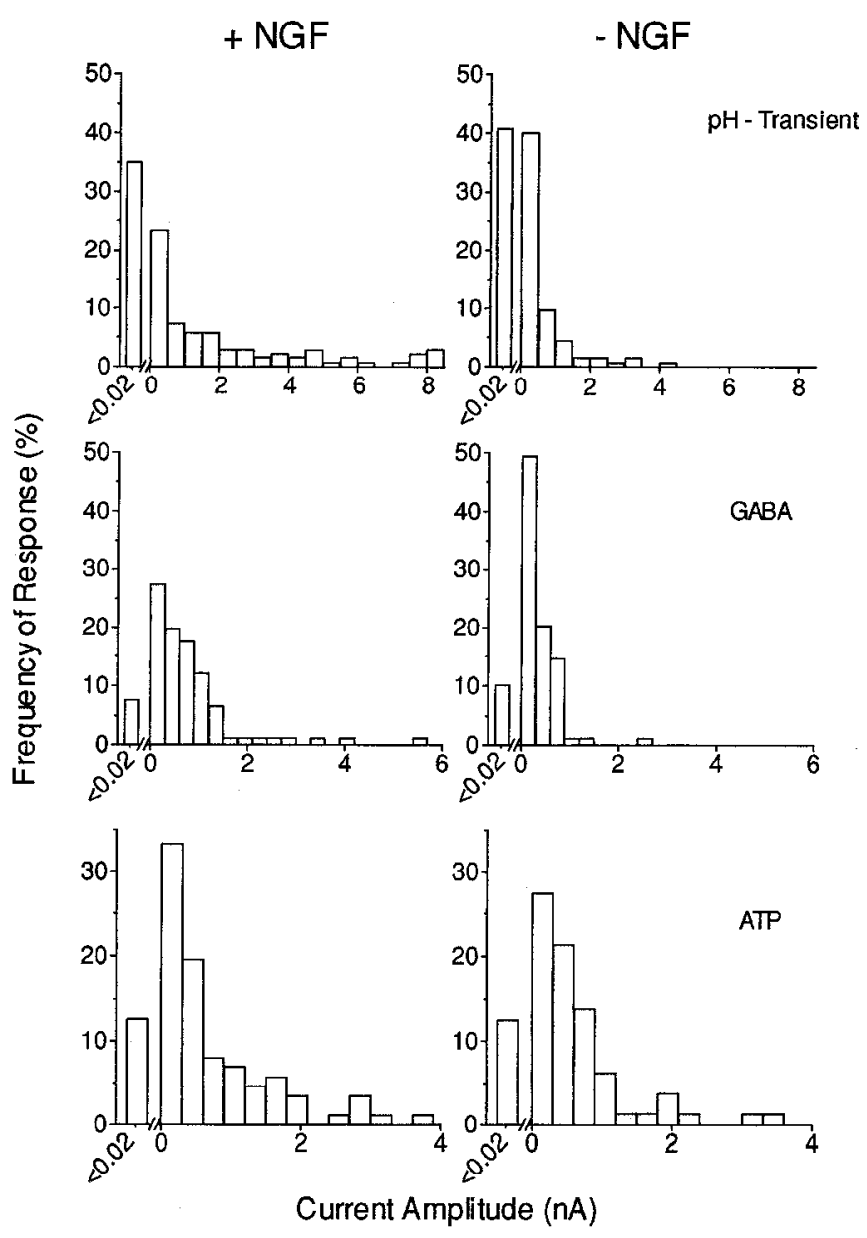

Figure 4. Frequency distributions of amplitudes of the transient, low pH- (top), GABA- (middle), and ATP-evoked currents (bottom). Lefthand bars show percentage of neurons with no measurable current $(<20-30 \mathrm{pA})$. Neurons were cultured for 2 weeks in either NGF or NGF-free medium. 
Table 4. Comparison of GABA, ATP, and low pH (transient) sensitivity after 1 and 2 weeks in culture with or without NGF

\begin{tabular}{|c|c|c|c|c|c|c|c|}
\hline & & 1 week & & & 2 weeks & & \\
\hline & & $\mathrm{NGF}^{+}$ & $\mathrm{NGF}^{-}$ & $\begin{array}{l}\text { Ratio } \\
\text { NGF}^{-} \text {: } \\
\text { NGF }^{+}\end{array}$ & $\mathrm{NGF}^{+}$ & $\mathrm{NGF}^{-}$ & $\begin{array}{l}\text { Ratio } \\
\mathrm{NGF}^{-} \text {: } \\
\mathrm{NGF}^{+}\end{array}$ \\
\hline GABA & $P(R)$ & $82 \%(22 / 27)$ & $78 \%(31 / 40)$ & & $92 \%(84 / 91)$ & $90 \%(80 / 89)$ & \\
\hline & $A($ tot $)(\mathrm{nA})$ & $1.20 \pm 0.23$ & $0.83 \pm 0.17$ & $69.2 \%$ & $0.78 \pm 0.09$ & $0.36 \pm 0.04 \dagger$ & $46.2 \%$ \\
\hline & $A(R)(\mathrm{nA})$ & $1.47 \pm 0.24$ & $1.07 \pm 0.20$ & $72.8 \%$ & $0.85 \pm 0.10$ & $0.40 \pm 0.04 \dagger$ & $47.1 \%$ \\
\hline ATP & $P(R)$ & $75 \%(18 / 24)$ & $82 \%(32 / 39)$ & & $87 \%(76 / 87)$ & $88 \%(70 / 80)$ & \\
\hline & $A($ tot $)(\mathrm{nA})$ & $1.18 \pm 0.27$ & $1.13 \pm 0.18$ & $95.8 \%$ & $0.68 \pm 0.08$ & $0.67 \pm 0.09$ & $98.5 \%$ \\
\hline & $A(R)(\mathrm{nA})$ & $1.57 \pm 0.33$ & $1.31 \pm 0.20$ & $83.4 \%$ & $0.76 \pm 0.09$ & $0.76 \pm 0.10$ & $100 \%$ \\
\hline pH-transient & $P(R)$ & $67 \%(92 / 138)$ & $67 \%(83 / 123)$ & & $65 \%(89 / 137)$ & $59 \%(80 / 135)$ & \\
\hline & $A(\mathrm{tot})(\mathrm{nA})$ & $1.08 \pm 0.16$ & $0.78 \pm 0.14$ & $72.2 \%$ & $1.41 \pm 0.19$ & $0.36 \pm 0.06 \dagger$ & $25.5 \%$ \\
\hline & $A(R)(\mathrm{nA})$ & $1.62 \pm 0.23$ & $1.16 \pm 0.19$ & $71.6 \%$ & $2.17 \pm 0.26$ & $0.62 \pm 0.09+$ & $28.6 \%$ \\
\hline
\end{tabular}

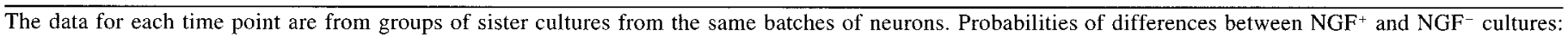
$*,<0.05 ; \dagger,<0.001$. No symbol indicates $P>0.05$.

$\mathrm{nA})$ than in 1 week $\mathrm{NGF}^{-}$neurons $(0.11 \pm 0.04 \mathrm{nA}$, Table 2 , $P<0.001)$ and although smaller than in 2 week $\mathrm{NGF}^{+}$neurons $(0.71 \pm 0.22 \mathrm{nA}$, Table 3$)$ the difference was not significant $(P$ $>0.2$ ). The recovery of proton sensitivity paralleled that for capsaicin sensitivity. Again while some $\mathrm{NGF}^{-1+}$ neurons responded to both agents others were unresponsive.

\section{GABA sensitivity}

The presence or absence of NGF made no difference to the proportion of GABA $(100 \mu \mathrm{M})$ sensitive DRG neurons, and $P(R)$ values of $78-92 \%$ were found in $\mathrm{NGF}^{+}$and $\mathrm{NGF}^{-}$neurons after 1 or 2 weeks in culture (see Table 4). However, the relative amplitude of the responses to GABA declined progressively in $\mathrm{NGF}^{-}$cultures. $A(R)$ in 1 week $\mathrm{NGF}^{-}$neurons was $72.8 \%$ of the value in 1 weck $\mathrm{NGF}^{+}$sister cultures, although this change was not statistically significant $(P=0.096)$. A further reduction in GABA sensitivity was noted after another week in culture

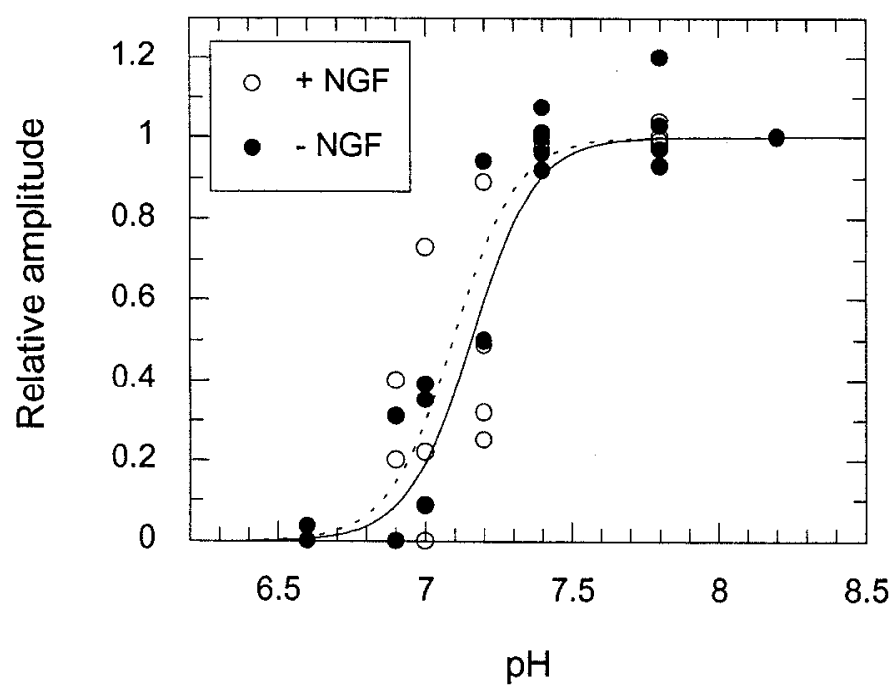

Figure 5. $\mathrm{pH}$ dependence of inactivation for the transient, low $\mathrm{pH}$ evoked current. Neurons were challenged with pH 5.8 medium after equilibration in solutions of varying $\mathrm{pH}$ (abscissa). Responses were normalized to the response measured after stepping from $\mathrm{pH} 8.2$ to 5.8 . Lines show sigmoidal plots fitted assuming a stoichiometry of $4 \mathrm{H}^{+}$to 1 "binding site" (Konnerth et al., 1987); estimated half-maximal inactivations were at $\mathrm{pH} 7.15\left(\mathrm{NGF}^{+}\right.$, solid line $)$and $\mathrm{pH} 7.09\left(\mathrm{NGF}^{-}\right.$, dotted line).
(Fig. $3 c, d$; Table 4) when $A(R)$ in the 2 week NGF- neurons was significantly reduced to $47.1 \%$ of the value in $\mathrm{NGF}^{+}$neurons $(P<0.001)$ and the distribution of current amplitudes was skewed further towards the smaller values (Fig. 4). This reduction in GABA sensitivity was unrelated to any difference in neuronal size (see below), as $A(R)$ was still less in the 2 week $\mathrm{NGF}^{-}$neurons when the currents were normalized for cell capacitance $\left(\mathrm{NGF}^{+} 27.2 \pm 3.8 \mathrm{pA} / \mathrm{pF}, n=84 ; \mathrm{NGF}^{-} 13.0 \pm 1.3\right.$ $\mathrm{pA} / \mathrm{pF}, n=79$ ).

\section{ATP sensitivity}

Ten micromolar ATP evoked a depolarizing inward current in $85.6 \%(267 / 312)$ of neurons tested (Fig. 3e,f). ATP sensitivity appeared to be unaffected by the presence or absence of NGF over a 2 week culture period (see Figs. 3,4 ). $P(R)$ was not decreased in $\mathrm{NGF}^{-}$cultures compared with $\mathrm{NGF}^{+}$cultures after 1 or weeks (Table 4 ) and $A(R)$ was not significantly different in the two conditions even after 2 weeks in culture. The absence of any decrease in ATP sensitivity in $\mathrm{NGF}^{-}$cultures was supported by calculation of the current density normalized for either cell capacitance or cell size (e.g., 2 weeks $\mathrm{NGF}^{+}$neurons 2.21 $\pm 0.26 \mathrm{p} \Lambda / \mathrm{pF}, 2$ weeks $\mathrm{NGF}^{-}$neurons $2.47 \pm 0.28 \mathrm{p} \Lambda / \mathrm{pF}$ ).

\section{General neuronal membrane properties}

The presence or absence of NGF had no obvious effect on membrane potential. Measured resting potentials after either one $\left(\mathrm{NGF}^{+}-49.4 \pm 1.0 \mathrm{mV}, n-83, \mathrm{NGF}^{-}-48.8 \pm 1.6 \mathrm{mV}, n\right.$ $=55)$ or 2 weeks in culture $\left(\mathrm{NGF}^{+}-48.8 \pm 0.7 \mathrm{mV} n=146\right.$, $\mathrm{NGF}^{-}-48.0 \pm 0.1 \mathrm{mV} n=140$ ) were not significantly different $(P>0.2)$. Cell capacitance was also similar for neurons cultured for 1 week in the two conditions $\left(\mathrm{NGF}^{+} 32.2 \pm 1.4\right.$ $\mathrm{pF}, n=85 ; \mathrm{NGF}^{-} 31.1 \pm 1.8 \mathrm{pF}, n=54, P=0.6$ ), whereas after 2 weeks a difference in capacitance of the sampled neurons was noted $\left(\mathrm{NGF}^{+} 34.6 \pm 1.1 \mathrm{pF}, n=143 ; \mathrm{NGF}^{-} 29.9 \pm 0.2\right.$ $\mathrm{pF}, n=139, P<0.01)$. This difference can be accounted for by the smaller size and therefore smaller surface area of neurons studied electrophysiologically in the $\mathrm{NGF}^{-}$cultures (diameter, $\mathrm{NGF}^{+} 24.25 \pm 0.28 \mu \mathrm{m}, \mathrm{NGF}^{-} 22.61 \pm 0.29 \mu \mathrm{m} ; P<0.01$ ). A small decrease in capacitance of mouse cultured DRG neuron following NGF withdrawal was also noted by Coan et al., 1994).

\section{${ }^{86} \mathrm{Rb} \mathrm{b}^{+}$efflux experiments}

${ }^{86} \mathrm{Rb}^{+}$efflux was used to test the responses of populations of DRG neurons to various stimuli. ${ }^{86} \mathrm{Rb}^{+}$efflux was measured in 
A

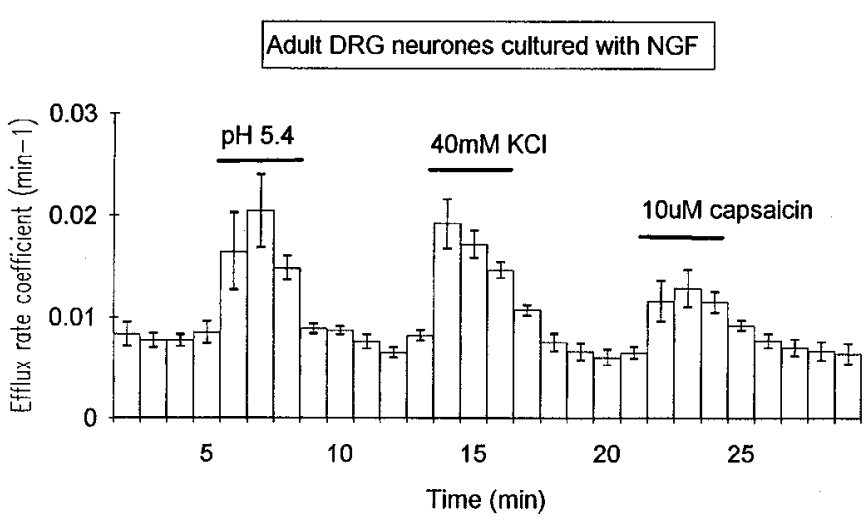

B

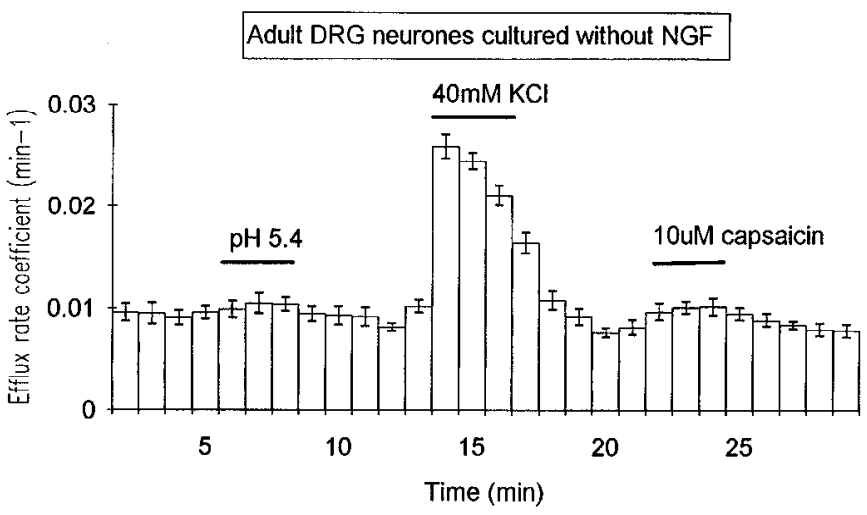

Figure 6. $\quad{ }^{86} \mathrm{Rb}^{+}$cfflux from DRG ncurons cvoked by scquential 3 min challenges with $\mathrm{pH} 5.4$ medium, high $(40 \mathrm{mM}) \mathrm{K}^{+}$and $10 \mu \mathrm{M}$ capsaicin. Neurons were cultured for 2 weeks either with or without NGF.

response to sequential 3 minute challenges with low $\mathrm{pH}(5.4)$, high potassium $(40 \mu \mathrm{M} \mathrm{KCl})$ and a high concentration of capsaicin (10 mM). We have shown elsewhere (Bevan et al., 1992) that the ${ }^{8} \mathrm{~Kb}^{+}$efflux response to $10 \mu \mathrm{M}$ capsaicin is inhibited by the competitive capsaicin antagonist, capsazepine, and so represents a selective effect on DRG neurons. All three stimuli evoked large increases in the rate of efflux in $1-2$ week $\mathrm{NGF}^{+}$ cultures. The efflux responses to both low $\mathrm{pH}$ solutions and capsaicin were substantially reduced in 1 week $\mathrm{NGF}^{-}$cultures, whereas the efflux produced by the high potassium solution was unchanged, or slightly increased. In 2 week NGF- cultures, the low $\mathrm{pH}$ and capsaicin-induced effluxes were almost completely lost while high potassium solutions could still evoke a large efflux (Fig. 6). The results of these efflux studies agree well with our electrophysiological findings and indicate that the loss of capsaicin evoked and sustained proton evoked currents is unlikely to be due to any effect of replating the neurons.

\section{Discussion}

The sensitivity of DRG neurons to capsaicin and protons did not vary with time in culture in medium containing NGF whereas GABA and ATP sensitivity declined. For all agonists tested, chemosensitivity did not increase when the DRG neurons were cultured with a high concentration $(200 \mathrm{ng} / \mathrm{ml})$ of NGF. This was shown by the comparison of responses from cultured neurons and acutely dissociated neurons. Any change in chemosensitivity when cells were deprived of NGF can therefore be at- tributed to a loss of sensitivity rather than an NGF-mediated increase in sensitivity in the "control," NGF-treated group.

Our data show that NGF can regulate two types of protonactivated currents as well as GABA sensitivity in adult cultured rat DRG neurons. The effects are similar to those previously described for the capsaicin-activated conductance (Winter et al., 1988) although the responses to the various agents were reduced at different rates in NGF-free medium. Not all membrane properties are NGF regulated. ATP sensitivity, resting potential and the depolarization evoked release of ${ }^{86} \mathrm{Rb}^{+}$, which reflects the activity of voltage gated $\mathrm{K}^{+}$channels, were not obviously influenced by the presence or absence of NGF.

The effects of NGF were most pronounced for the capsaicin and sustained proton evoked currents. For the sustained proton evoked current, NGF deprivation resulted in a reduction in both the number of responsive neurons $[P(R)]$ and the amplitudes of the currents $[A(R)$ and $A($ tot $)]$. This was reflected in the almost total abolition of proton ( $\mathrm{pH} 5.4$ ) evoked ${ }^{86} \mathrm{Rb}$ efflux in $\mathrm{NGF}^{-}$ cultures. The loss of proton sensitivity was reversible as $P(R)$, $A(R)$, and $A($ tot $)$ were increased when $\mathrm{NGF}^{-}$neurons were exposed to NGF for a further week. The reduced amplitude of the response of $\mathrm{NGF}^{-}$neurons was not due to any obvious change in the $\mathrm{pH}$ threshold for activation. Similarly, Winter et al. (1988) showed that the loss of capsaicin responses was not due to any shift in the concentration-response curve to higher agonist concentrations.

The capsaicin induced currents and the sustained proton evoked currents were rapidly lost when NGF was removed and were restored to a similar degree when NGF was added back to the culture medium. Bevan and Yeats (1991) found that DRG neurons had either both types of conductance or neither, which raised the possibility that both protons and capsaicin open the same channel. Their co-regulation by NGF supports this idea, which is also consistent with the preliminary results from single channel recordings (Bevan et al., 1993).

The transient current evoked by exposure to low $\mathrm{pH}$ solutions (Krishtal and Pidoplichko, 1980, 1981; Konnerth et al., 1987) was also reduced when neurons were cultured in the absence of NGF. In this case the loss of sensitivity was slower than for both the sustained proton evoked current and the response to capsaicin. The smaller size of the transient current in $\mathrm{NGF}^{-}$neurons cannot be ascribed to a difference in channel inactivation as $\mathrm{NGF}^{+}$and $\mathrm{NGF}^{-}$neurons showed similar $\mathrm{pH}$-current amplitude relationships (half inactivation at $\mathrm{pH} 7.1$ ). Furthermore a reduced proton sensitivity in NGF deprived neurons was still seen after maximizing the amplitude of the response by alkalinization to $\mathrm{pH} 7.8$ before challenge with the acid solution. We also found no evidence that removal of $\mathrm{NGF}$ shifted the $\mathrm{pH}$ activation curve to more acidic values. Together these results indicate that the reduction in transient current amplitude represents a genuine loss of functional membrane ion channels rather than a modification in their $\mathrm{pH}$ activation/inactivation characteristics.

Removal of NGF also caused a progressive slow loss of GABA sensitivity and $A(R)$ declined to $47 \%$ of the control $\mathrm{NGF}^{\prime}$ value over 2 weeks. We have no data on the reversibility of this effect. Aguayo and White (1992) did not find any significant NGF-dependent change in GABA sensitivity in similar experiments with adult rat DRG neurons in culture. This discrepancy may be due to the lower concentrations of NGF and the small sample sizes used in their experiments. Previous studies have shown that GABA sensitivity of dorsal roots was attenuated in vivo when the distal nerve was transected (Kingery 
et al., 1988; Bhisitkul et al., 1990) and the authors postulated that a reduced supply of NGF could account for this change in chemosensitivity. No obvious decrease was noted in the first week, but GABA induced depolarizations were reduced by 40 $50 \% 12-21 \mathrm{~d}$ after surgery. The loss of GABA sensitivity could be ameliorated if the nerve was allowed to regenerate, possibly because Schwann cells were now able to provide NGF to the regenerating nerve fibers (Bhisitkul et al., 1990). Our results showing a relatively slow loss of GABA sensitivity when DRG neurons are deprived of NGF are consistent with these in vivo data.

Only $40 \%$ of adult rat DRG neurons in culture express mRNA for trkA (De Felipe and Hunt, 1994), which is a component of the high affinity $\mathrm{NGF}$ receptor (see, e.g., Meakin and Shooter, 1992). This is similar to the percentage of neurons that are sensitive to capsaicin and show the sustained proton evoked current. Furthermore, NGF regulated these chemosensitivities in most neurons which suggests an almost complete correspondence hetween the populations. Larger proportions of neurons showed the transient proton evoked current (53-67\%) and responded to GABA (78-92\%). In these cases, it is unclear if the chemosensitivities of all neurons are reduced in NGF-free medium or whether the changes are restricted to the trkA expressing neurons.

Our data show that NGF regulates the sensitivity of DRG neurons to capsaicin, protons, and GABA and that the NGFregulated reduction in sensitivity occurs at different rates (capsaicin $=$ sustained proton $>$ transient proton $>$ GABA). In contrast, ATP sensitivity was not regulated by NGF. Estimated halftimes for the loss of chemosensitivities are, for capsaicin and sustained proton, 2-3 d; transient proton, $\sim 9 \mathrm{~d}$; GABA, 12-13 $\mathrm{d}$. The electrophysiological estimates for the ratc of loss of capsaicin sensitivity agree well with the more detailed time course shown by ${ }^{45} \mathrm{Ca}$ uptake experiments (half-time $3 \mathrm{~d}$, Winter et al., 1988).

NGF belongs to a family of related molecules that is important in the development and maintenance of sensory neurons. Although NGF is not required for the survival of the majority of adult DRG neurons, it can affect the expression of substance $P$ and CGRP (Lindsay and Harmar, 1989; Lindsay et al., 1989), two neuropeptides that may be involved in pain and neurogenic inflammation. Studies on rat nodose ganglion neurons in culture have illustrated that NGF promotes the expression of acetylcholine sensitivity by increasing the size of the currents but not the proportion of responsive neurons (Mandelzys and Cooper, 1992). Thus our data and other studies show that neuronal membrane chemosensitivity as well as neuropeptide content can be influenced by NGF. Other experiments have illustrated that NGF can also regulate the expression of ion channels involved in action potential generation (Chalazonitis et al., 1987; Aguayo et al., 1991; Aguayo and White 1992Ritter and Mendell, 1992). Voltage-clamp studies of adult rat cultured DRG neurons have shown that expression of TTX insensitive sodium currents requires NGF (Aguayo et al., 1991; Aguayo and White 1992), although the same experiments suggest that the TTX-sensitive sodium current is not downregulated by NGF deprivation. This finding, together with our ohservation that the responses to ATP were not regulated by NGF in cultured DRG neurons, indicates that not all ion channels are regulated in the same way.

In vivo, NGF is made in tissues that are innervated by peripheral neurons, and is retrogradely transported back to the DRG cell bodies (Goedert et al., 1981; Gordon, 1983) where it acts to regulate cellular phenotype. NGF levels can be greatly elevated in inflamed tissue (Otten, 1991; Woolf et al., 1994) and increased availability of NGF may upregulate production of neuropeptides in neurons innervating that tissue (Donnerer et al., 1992; Woolf et al., 1994). Moreover, when NGF is supplied to peripheral nerve in vivo, it dramatically increases the responses of dorsal horn neurons to a standard C-fiber stimulus of the NGF treated nerve (Lewin et al., 1992). Recent studies have shown that systemic application of NGF can cause thermal and me chanical hyperalgesia (Lewin et al., 1993), and that antisera that neutralize NGF can prevent the development of hyperalgesia in adjuvant-injected rat paws (Lewin and Mendell, 1992; Woolf et al., 1994). Changes in chemosensitivity in inflammation have not been reported. We found no evidence that any of the chemosensitivities studied were increased by exposure to high levels of NGF in vitro. Furthermore capsaicin sensitivity, as judged by ${ }^{45} \mathrm{Ca}^{2+}$ uptake, is not increased in DRG neurons innervating inflamed tissues (unpublished observations). These findings do not rule out the possibility that raised concentrations of NGF can upregulate the chemosensitivity of a subpopulation of neurons which innervate tissues that normally produce very low levels of NGF.

The sensory nerves may be deprived of an adequate supply of NGF in certain neuropathic conditions, some of which involve nerve damage. Changes in neuronal phenotype consistent with NGF-deprivation have been observed in experimentally induced diabetic rats (Brewster et al., 1994). In such conditions the neurons may display reduced chemosensitivity. Nerve section has been shown to decrease DRG neuron capsaicin sensitivity as judged by ${ }^{45} \mathrm{Ca}^{2+}$ uptake assays (unpublished observations). The sensitivity to the inhibitory transmitter GABA is also decreased by nerve section (Kingery et al., 1988) and NGF deprivation. This change in GABA sensitivity may augment the excitatory synaptic transmission between these primary afferents and spinal cord neurons. These observations, taken together, imply that NGF plays an important role in determining the chemosensitivity and "connectivity" of sensory neurons in hyperalgesic and neuropathic states.

\section{References}

Aguayo LG, White G (1992) Effects of nerve growth factor on TTXand capsaicin-sensitivity in adult rat sensory neurons. Brain Res 570: $61-67$.

Aguayo LG, Weight FF, White G (1991) TTX-sensitive action potentials and excitability of adult rat sensory neurons cultured in serum and exogenous nerve growth factor-free medium. Neurosci Lett 121: $88-92$.

Bevan S, Yeats J (1991) Protons activate a cation conductance in a subpopulation of rat dorsal root ganglion neurons. J Physiol (Lond) 433:145-161.

Bevan S, Hothi S, Hughes G, James IF, Rang HP, Shah K, Walpole CSJ, Yeats JC (1992) Capsazepine: a competitive antagonist of the sensory neurone excitant capsaicin. Br J Pharmacol 107:544-552.

Bevan S, Forbes CA, Winter J (1993) Protons and capsaicin activate the same channels in rat isolated dorsal root ganglion neurones. $J$ Physiol (Lond) 459:401P.

Bhisitkul RB, Kocsis JD, Gordon TR, Waxman SG (1990) Trophic influence of the distal nerve segment on $\mathrm{GABA}_{\wedge}$ receptor expression in axotomized adult sensory neurons. Exp Neurol 109:273-278.

Brewster WJ, Fernyhough P, Diemel LT, Mohiuddin L, Tomlinson DR (1994) Diabetic neuropathy, nerve growth factor and other neurotrophic factors. Trends Neurosci 17:321-325.

Chalazonitis A, Peterson ER, Crain SM (1987) Nerve growth factor regulates the action potential duration of mature sensory neurons. Proc Natl Acad Sci USA 84:289-293.

Coan EJ, Galdzicki Z, Rapoport SI (1994) Effects of nerve growth factor on whole-cell currents and other electrical membrane proper- 
ties in cultured dorsal root ganglion neurons from normal and trisomy 16 mice. Brain Res 650:161-165.

Crowley C, Spencer SD, Nishimura MC, Chen KS, Pitts-Meek S, Armanini MP, Ling LH, McMahon SB, Shelton D, Levinson AD, Phillips HS (1994) Mice lacking nerve growth factor display perinatal loss of sensory and sympathetic neurones yet develop basal forebrain cholinergic neurons. Cell 76:1001-1011.

De Felipe C, Hunt SP (1994) The differential control of c-Jun expression in regenerating sensory neurones and their associated glial cells. J Neurosci 14:2911-2923.

Donnerer J, Schuligoi R, Stein S (1992) Increased content and transport of substance $\mathrm{P}$ and calcitonin gene-related peptide in sensory nerves innervating inflamed tissue: evidence for a regulatory function of nerve growth factor in vivo. Neuroscience 49:693-698.

Fenwick EM, Marty A, Neher E (1984) A patch clamp study of bovine chromaffin cells and of their sensitivity to acetylcholine. J Physiol (Lond) 331:577-597.

Furth ME, Davis LJ, Flcurdclys B, Scolnik EM (1982) Monoclonal antibodies to the $\mathrm{p} 21$ products of the transforming gene of Harvey murine sarcoma virus and of the cellular ras gene family. J Virol 43: 294-304.

Goedert M, Stoeckel K, Otten U (1981) Biological importance of the retrograde transport of nerve growth factor in sensory neurones. Proc Natl Acad Sci USA 78:5895-5898.

Gordon T (1983) The dependence of peripheral nerves on their target organs. In: Somatic and autonomic muscle interaction (Burnstock G, Vrbova G, O'Brien RA, eds), pp 289-325. Amsterdam; Elsevier.

Gorin PD, Johnson EM (1980) Effects of long term nerve growth factor deprivation on the nervous system of the adult rat: an experimental autoimmune approach. Brain Res 198:27-42.

Johnson EM, Gorin PD, Brandeis LD, Pearson J (1980) Dorsal root ganglion neurones are destroyed by exposure in utero to maternal antibody to nerve growth factor. Science 219:916-918.

Kingery WS, Fields RD, Kocsis JD (1988) Diminished dorsal root GABA sensitivity following chronic peripheral nerve injury. Exp Neurol 100:478-490.

Konnerth A, Lux HD, Morad M (1987) Proton-induced transformation of calcium channels in chick dorsal root ganglion cells. J Physiol (Lond) 386:603-633.

Krishtal OA, Pidoplichko VI (1980) A receptor for protons in the nerve cell membrane. Neuroscience 5:2325-2327.

Krishtal OA, Pidoplichko VI (1981) A receptor for protons in the membrane of sensory neurons may participate in nociception. Neuroscience 6:2599-2601.

Lewin GR, Mendel LM (1992) Regulation of cutaneous C fiber heat nociceptors by nerve growth factor in the developing rat. J Physiol (Lond) 452:43P.

I ewin GR, Ritter AM, Mendel IM (1992a) On the role of nerve growth factor in the development of myelinated nociceptors. J Neurosci 12:1896-1905.

Lcwin GR, Winter J, McMahon SB (1992b) Regulation of afferent connectivity in the adult spinal cord by nerve growth factor. Eur $\mathbf{J}$ Neurosci 4:700-707

Lewin GR, Ritter AM, Mendel LM (1993) Nerve growth factor-induced hyperalgesia in the neonatal and adult rat. J Neurosci 13:21362148.

Lindsay R (1988a) The role of neurotrophic growth factors in development, maintenance and regeneration of sensory neurones. In: The making of the nervous system (Parnavelas J, Stern CD, Sterling RV, eds), pp 148-165. London: Oxford UP.

Lindsay R (1988b) Nerve growth factor enhances regeneration but is not required as a survival factor for adult sensory neurones. J Neurosci 8:2394-2405.

Lindsay RM, Harmar AJ (1989) Nerve growth factor regulates expression of neuropeptide genes in adult sensory neurones. Nature 337:362-364.

Lindsay RM, Lockett C, Sternberg J, Winter J (1989) Neuropeptide expression in cultures of adult sensory neurones: modulation of substance $\mathrm{P}$ and calcitonin gene-related peptide levels by nerve growth factor Neuroscience 33.53-65.

Lui L, Simon SA (1994) A rapid capsaicin-activated current in trigeminal ganglion neurons. Proc Natl Acad Sci USA 91:738-741.

Mandelzys A, Cooper E (1992) Effects of ganglionic satellite cells and NGF on the expression of nicotinic acetylcholine currents by rat sensory neurones. J Neurophysiol 67:1213-1221.

Meakin SO, Shooter EM (1992) The nerve growth factor family of receptors. Trends Neurosci 15:323-331.

Otten UH (1991) Nerve growth factor: a signalling protein between the nervous and the immune systems. In: Towards a new pharmacotherapy of pain (Basbaum AI, Besson JM, eds). London: Wiley.

Petersen M, LaMotte RH (1993) Effect of protons on the inward current evoked by capsaicin in isolated dorsal root ganglion cells. Pain $54: 37-42$

Pidoplichko VI (1992) Ammonia and proton gated channel populations in trigeminal ganglion neurons. Gen Physiol Biophys 11:39-48.

Rang HP, Bevan S, Dray A (1991) Chemical activation of nociceptive peripheral neurones. Br Med Bull 3:534-548.

Ritter AM, Mendell LM (1992) Somal membrane properties of physiologically identified sensory neurons in the rat: effects of nerve growth factor. J Neurophysiol 68:2033-2041.

Ritter AM, Lewin GR, Kremer NE, Mendell LM (1991) Requirement for nerve growth factor in the development of myelinated nociceptors in vivo. Nature 350:500-501.

Ritter AM, Lewin GR, Mendell LM (1993) Regulation of myelinated nociceptor function by nerve growth factor in neonatal and adult rats. Brain Res Bull 30:245-249.

Weskamp G, Otten U (1987) An enzyme-linked immunoassay for nerve growth factor (NGF): a tool for studying regulatory mechanisms involved in NGF production in brain and in peripheral tissues J Neurochem 48:1779-1786.

Winter J (1987) Characterization of capsaicin-sensitive neurones in adult rat dorsal root ganglion cultures. Neurosci Lett 80:131-110.

Winter J, Forbes CA, Sternberg J, Lindsay RM (1988) Nerve growth factor (NGF) regulates adult rat cultured dorsal root ganglion neuron responses to capsaicin. Neuron 1:973-981.

Winter J, Walpole CSJ, Bevan S, James IF (1993) Characterization of resiniferatoxin binding sites on sensory neurons: co-regulation of resiniferatoxin binding and capsaicin-sensitivity in adult rat dorsal root ganglia. Neuroscience 57:747-757.

Wong J, Oblinger MM (1991) NGF rescues substance P expression but not neurofilament or tubulin gene expression in axotomised sensory neurones. J Neurosci 11:543-552.

Wood JN, Winter J, James IF, Rang HP, Yeats J, Bevan S (1988) Capsaicin-induced ion fluxes in dorsal root ganglion cells in culture. J Neurosci 8:3208-3220.

Woolf CJ, Safieh-Garabedian B, Ma Q-P, Crilly P, Winter J (1994) Nerve growth factor contributes to the generation of inflammatory sensory hypersensitivity. Neuroscience 62:327-331. 